\title{
Iron(III) Chelating Resins. VI. Stability Constants of Iron(III)-Ligand Complexes on Insoluble Polymeric Matrices
}

\author{
MINHUA FENG, LEEN VAN DER DOES, * and ADRIAAN BANTJES \\ Department of Chemical Technology, Biomaterials Section, University of Twente, P.O. Box 217, \\ 7500 AE Enschede, The Netherlands
}

\begin{abstract}
SYNOPSIS
A method is presented for the determination of stability constants of iron(III)-ligand complexes on insoluble polymeric matrices based on a competition chelation reaction for iron(III) of the resin with a soluble chelator. Stability constants $\left(K^{\prime}\right)$ were calculated for iron(III)ligand complexes on DFO-Sepharose gel, HMP-Sepharose gel, AHMP-HEMA resin, and AHMP-DMAA resin. In these resins, desferrioxamine B (DFO, hexadentate ligand) or the 3-hydroxy-2-methyl-4(1H)-pyridinone (HMP, bidentate ligand) was bound on insoluble polymeric matrices. The average values $\left(\log K^{\prime}\right.$ ) were: 26.6 (DFO-Sepharose); 37.9 (HMPSepharose); 27.2 (AHMP-HEMA); and 39.9 (AHMP-DMAA). The stability constants of the insoluble iron(III) complexes on the resins were compared with those of the corresponding soluble iron(III) complexes. The effect of immobilization on the constants was discussed, and it was found that a higher hydrophilicity and stability of a resin resulted in an increase of the stability constant, whereas steric hindrance decreased the stability constant. (C) 1995 John Wiley \& Sons, Inc.
\end{abstract}

\section{INTRODUCTION}

A number of investigators have studied the synthesis and properties of iron(III) chelating polymers, chiefly with poly(hydroxamic acid)s and desferrioxamine immobilized resins. ${ }^{1-5}$ More limited consideration, however, has been given to the measurement of stability constants of iron(III)-ligand complexes on insoluble polymeric matrices. ${ }^{6-8}$

A method of estimating the stability constants of insoluble polymer iron(III) chelates was proposed by Ramirez and Andrade. ${ }^{6}$ However, the results of that work and also the work of Horowitz, Margel, and Shimoni ${ }^{7}$ are doubtful because an incorrect definition of the stability constant was used, whereas the influence of $\mathrm{Fe}(\mathrm{OH})_{3}$ formation in the equilibrium reaction was not taken into account. Furthermore, by using their procedure it was difficult to analyze accurately the iron(III)

* To whom correspondence should be addressed. Journal of Applied Polymer Science, Vol. 56, 1231-1237 (1995) (C) 1995 John Wiley \& Sons, Inc. CCC 0021-8995/95/101231-07 concentration because of the formation of $\mathrm{Fe}(\mathrm{OH})_{3}$, which precipitates easily at neutral $\mathrm{pH}$. It has been reported that the stability constant of an insoluble chelating resin-metal complex cannot be measured directly because of the insolubility of the chelating resin ${ }^{9}$; also, because $\mathrm{Fe}^{3+}$ precipitates very readily in the absence of other chelators, a strong acid must usually be present to counteract the tendency toward $\mathrm{Fe}(\mathrm{OH})_{3}$ formation in solutions $\left(K_{s p}=10^{-39}\right) .^{10}$

Recently, the synthesis, characterization, and properties of several iron(III) chelating resins have been investigated by us ${ }^{11-14}$ as part of a project to study their utilization for iron removal from different systems, for bacterial growth inhibition, and for treatment of iron overload in blood. Although other factors come into play, it is clear that the stability constant of an iron(III)-ligand complex on a resin is important in determining which resin will be better in practical use. The stability constants should also be very useful in comparing the relative affinity among the chelating resins as well as with the corresponding soluble chelators. 
Generally, the methods of studying the stability constants of insoluble complexes are the ligand competition method, the metal competition method, the proton competition method, and the $\mathrm{pH}$ of the decomplexing method. ${ }^{15}$ In the present study, the stability constants were determined of iron(III)-ligand complexes on DFO-Sepharose gel, ${ }^{11}$ HMPSepharose gel, ${ }^{12}$ AHMP-HEMA resin, ${ }^{13}$ and AHMP-DMAA resin..$^{14}$ In these resins, desferrioxamine $B$ (DFO, hexadentate ligand) or the 3-hydroxy-2-methyl-4(1H)-pyridinone group (HMP, bidentate ligand) was bound on insoluble polymeric matrices. Because of the extremely high affinity of the chelating resins for iron(III), the ligand competition method was used for the determination of the stability constants.

In addition, because few investigations ${ }^{16}$ have been made concerning the relationship between the stability constant of an insoluble metal ion-ligand complex and of the corresponding soluble complex, the effect of immobilization on the affinity was discussed from the viewpoint of the influence of the polymeric matrix.

In the present paper, a method is described to estimate the stability constants of the insoluble iron(III)-ligand complexes. The stability constants of the iron(III) chelating resins were determined; the values are discussed, as well as the effect of immobilization on the affinity of the ligands.

\section{CALCULATION OF STABILITY CONSTANTS}

The ligand competition method is usually applied for the determination of stability constants of soluble iron(III)-ligand complexes. ${ }^{17}$ Winston and Kirchner reported the stability constants for several iron(III) poly(hydroxamic acid)s complexes measured by competition experiments between iron(III), the polymer, and ethylenediamine tetraacetic acid (EDTA) ${ }^{18}$ In our study, a competitive chelation of an insoluble chelating resin and a water-soluble chelator for iron(III) was used to determine the stability constants of iron(III)-ligand complexes on insoluble polymeric matrices. Although immobilization of a ligand on a polymeric matrix might lead to a change in the affinity of the ligand or of the composition of the metal ion-ligand complex, it was assumed that the ligand competition method could also be used for the insoluble iron(III)-ligand complexes. The fundamental point of the method is the distribution of iron(III) between a soluble chelator and an insoluble chelating resin. When equilibrium is established, a definite relationship should exist be- tween the stability constants of the soluble iron(III) complex and the insoluble iron(III) complex.

In practical measurements, the competition reaction can be performed either by addition of the resin to a solution of the soluble complex or by adding the soluble chelator to the insoluble resiniron(III) complex. A suitable soluble chelator must be chosen to obtain a convenient distribution of iron between the resin and the soluble chelator. Competition by EDTA was used to determine the stability constants for DFO-Sepharose gel and AHMPHEMA resin, whereas for HMP-Sepharose gel and AHMP-DMAA resin, 1-ethyl-3-hydroxy-2-methyl$4(1 \mathrm{H})$-pyridinone (EHMP) was used as the competitive chelator.

Soluble hexadentate ligands such as DFO form a 1 : 1 iron(III)-ligand complex. ${ }^{19}$ Assuming also a $1: 1$ iron(III)-ligand complex on the DFO-Sepharose gel, competition with EDTA will give rise to two chelation reactions:

$$
\begin{gathered}
\mathrm{Fe}+\mathrm{L} \rightleftharpoons \mathrm{FeL} \\
K=\frac{[\mathrm{FeL}]}{[\mathrm{Fe}][\mathrm{L}]} \\
\mathrm{Fe}+\mathrm{L}^{\prime} \rightleftharpoons \mathrm{FeL}^{\prime} \\
K^{\prime}=\frac{[\mathrm{FeL}]}{[\mathrm{Fe}]\left[\mathrm{L}^{\prime}\right]}
\end{gathered}
$$

where $\mathrm{L}$ is the soluble ligand and $\mathrm{L}^{\prime}$ the immobilized ligand on the resin. For the sake of brevity, all charges have been omitted. In the equilibrium situation, the system can be represented in the following way:

$$
\begin{gathered}
\mathrm{FeL}+\mathrm{L}^{\prime} \rightleftharpoons \mathrm{FeL}^{\prime}+\mathrm{L} \\
K q=\frac{\left[\mathrm{FeL}^{\prime}\right][\mathrm{L}]}{[\mathrm{FeL}]\left[\mathrm{L}^{\prime}\right]}=\frac{\left[\mathrm{FeL}^{\prime}\right]}{[\mathrm{Fe}]\left[\mathrm{L}^{\prime}\right]} \times \frac{[\mathrm{Fe}][\mathrm{L}]}{[\mathrm{FeL}]}=\frac{K^{\prime}}{K}
\end{gathered}
$$

It is then possible to calculate the stability constant $K^{\prime}$, when the constant $K$ and $K q$ are known. The value of $K$ for EDTA is known, ${ }^{20}$ and for the determination of $K q$, the following equations can be applied:

$$
\begin{gathered}
{[\mathrm{Fe}]_{t}=[\mathrm{FeL}]+\left[\mathrm{FeL}^{\prime}\right]} \\
{[\mathrm{L}]_{t}=[\mathrm{FeL}]+\Sigma\left[\mathrm{H}_{i} \mathrm{~L}\right]=[\mathrm{FeL}]+\left[\mathrm{EDTA}^{4-}\right]} \\
\times\left(1+K_{1}\left[\mathrm{H}^{+}\right]+K_{1} K_{2}\left[\mathrm{H}^{+}\right]^{2}+K_{1} K_{2} K_{3}\left[\mathrm{H}^{+}\right]^{3}\right. \\
\\
\left.+K_{1} K_{2} K_{3} K_{4}\left[\mathrm{H}^{+}\right]^{4}\right)
\end{gathered}
$$




$$
\begin{aligned}
{\left[\mathrm{L}^{\prime}\right]_{t}=} & {\left[\mathrm{FeL}^{\prime}\right]+\Sigma\left[\mathrm{H}_{i} \mathrm{~L}^{\prime}\right]=\left[\mathrm{FeL}^{\prime}\right]+\left[\mathrm{DFO}^{3-}\right] } \\
& \times\left(1+K_{1}^{\prime}\left[\mathrm{H}^{+}\right]+K_{1}^{\prime} K_{2}^{\prime}\left[\mathrm{H}^{+}\right]^{2}\right. \\
& \left.+K_{1}^{\prime} K_{2}^{\prime} K_{3}^{\prime}\left[\mathrm{H}^{+}\right]^{3}\right)
\end{aligned}
$$

where $[\mathrm{Fe}]_{t},[\mathrm{~L}]_{t}$, and $\left[\mathrm{L}^{\prime}\right]_{t}$ are total concentrations of iron(III), L, and $L^{\prime}$, respectively. $\Sigma\left[\mathrm{H}_{i} \mathrm{~L}\right]$ and $\Sigma\left[\mathrm{H}_{i} \mathrm{~L}^{\prime}\right]$ are the sum of the concentrations of consecutive protonated species of $L$ and $L^{\prime}$, respectively. $K_{1}, K_{2}, K_{3}$, and $K_{4}$ are the first, second, third, and fourth protonation constants for $\mathrm{EDTA}^{4-}$, which can be found in literature $.^{21} K_{1}^{\prime}, K_{2}^{\prime}$, and $K_{3}^{\prime}$ are the first, second, and third protonation constants for the immobilized ligand $\mathrm{DFO}^{3-}$, assuming that they are the same as for the free DFO. ${ }^{19}$

For the competition studies reported here, the assumption has been made that uncomplexed iron(III) was absent. Because $[\mathrm{Fe}]_{t},[\mathrm{~L}]_{t}$, and $\left[\mathrm{L}^{\prime}\right]_{t}$ are known, whereas the concentration of the soluble iron(III) complex [FeL] can be determined, the values of $\left[\mathrm{FeL}^{\prime}\right], \Sigma\left[\mathrm{H}_{i} \mathrm{~L}\right]$, and $\Sigma\left[\mathrm{H}_{i} \mathrm{~L}^{\prime}\right]$ can be calculated with eqs. (4), (5), and (6). [L] and [L'] were calculated from the values of $\Sigma\left[H_{i} L\right]$ and $\Sigma\left[\mathrm{H}_{i} \mathrm{~L}^{\prime}\right]$, literature values of protonation constants of $\mathrm{L}$ and $\mathrm{L}^{\prime}$, and the $\mathrm{pH}$ values of the system. With the value for $K q$, determined as indicated, it was possible to calculate the stability constant $K^{\prime}$ by using eq. (3).

With soluble bidentate ligands a number of complexes may be formed with iron(III), which depends on the iron, ligand, and hydrogen ion concentrations. ${ }^{22}$ For HMP ligands, however, only the cumulative stability constants with iron(III) $\left(\beta_{3}\right)$ were considered because it has been found that the ligand formed a $1: 3$ iron(III)-ligand complex; this complex was favored over a wide range of $\mathrm{pH}$ (pH 5-11) and of ligand-iron(III) ratios. ${ }^{23,24}$ In addition, the experiments were carried out with excess amounts of both soluble and insoluble ligands to ensure complete complexation in the solution and on the resin. Also, in the insoluble complexes, the occurrence of a $1: 3$ iron(III)-ligand ratio was assumed.

The method based on competition studies with EDTA was also used to determine the stability constant for the AHMP-HEMA resin. The mathematical treatment for the EDTA competition reaction was similar to that for the DFO-Sepharose gel and EDTA competition system. For the competition by EHMP, the AHMP-DMAA resin and EHMP competition system was taken as an example. In this system, $\mathrm{FeL}_{3}$ and $\mathrm{FeL}_{3}^{\prime}$ are the only iron(III)-containing species, and the corresponding formulas are as follows:

$$
\begin{aligned}
K & =\frac{\left[\mathrm{FeL}_{3}\right]}{[\mathrm{Fe}]\left[\mathrm{L}^{3}\right.} \\
K^{\prime} & =\frac{\left[\mathrm{FeL}_{3}^{\prime}\right]}{[\mathrm{Fe}]\left[\mathrm{L}^{\prime}\right]^{3}} \\
K q & =\frac{\left[\mathrm{FeL}_{3}^{\prime}\right][\mathrm{L}]^{3}}{\left[\mathrm{FeL}_{3}\right]\left[\mathrm{L}^{\prime}\right]^{3}}=\frac{K^{\prime}}{K} \\
{[\mathrm{Fe}]_{t} } & =\left[\mathrm{FeL}_{3}\right]+\left[\mathrm{FeL} L_{3}^{\prime}\right] \\
{[\mathrm{L}]_{t} } & =3\left[\mathrm{FeL}_{3}\right]+\Sigma\left[\mathrm{H}_{i} \mathrm{~L}\right] \\
{\left[\mathrm{L}_{t}\right]_{t} } & =3\left[\mathrm{FeL}_{3}^{\prime}\right]+\Sigma\left[\mathrm{H}_{i} \mathrm{~L}^{\prime}\right]
\end{aligned}
$$

where $L$ and $L^{\prime}$ denote the free and immobilized ligand (HMP), respectively. It has been found that at physiological $\mathrm{pH}$, HMP ligands remained quantitatively unprotonated, ${ }^{25,26}$ hence:

$$
\begin{aligned}
\Sigma\left[\mathrm{H}_{i} \mathrm{~L}\right] & =[\mathrm{L}] \\
\Sigma\left[\mathrm{H}_{i} \mathrm{~L}^{\prime}\right] & =\left[\mathbf{L}^{\prime}\right]
\end{aligned}
$$

$K$ for EHMP can be found in literature, ${ }^{22}$ and in a way similar to that described for the competitive studies with EDTA, the stability constant was determined.

\section{EXPERIMENTAL}

\section{Materials}

The DFO-Sepharose gel, prepared by coupling desferrioxamine $\mathrm{B}$ (DFO) to $\mathrm{CNBr}$-activated Sepharose 4B, had a DFO density of $21 \mu \mathrm{mol} / \mathrm{ml}$ gel. ${ }^{11}$ An HMP-Sepharose gel was used with a ligand density of $18 \mu \mathrm{mol} / \mathrm{ml}$ gel, which was derived from the immobilization of 1-(2-aminoethyl)-3hydroxy-2-methyl-4(1H)-pyridinone (HMP) on CNBr-activated Sepharose 4B. ${ }^{12}$ AHMP-HEMA resin and AHMP-DMAA resin were synthesized by the copolymerization of 1-( $\beta$-acrylamidoethyl)3-hydroxy-2-methyl-4(1H)-pyridinone (AHMP) with 2-hydroxyethyl methacrylate (HEMA) and N,N-dimethylacrylamide (DMAA), respectively, in the presence of a crosslinker. ${ }^{13,14}$ The ligand density of the AHMP-HEMA resin was 214 $\mu \mathrm{mol} / \mathrm{g} .{ }^{13}$ The AHMP-DMAA resin was used with the ligand density of $460 \mu \mathrm{mol} / \mathrm{g} .{ }^{14}$ The structures of the iron(III) chelating resins are shown in Figure 1.

EHMP was prepared according to a literature method. ${ }^{27}$ EDTA was obtained from Merck. $\mathrm{FeCl}_{3} \cdot 6 \mathrm{H}_{2} \mathrm{O}$ (Merck) was used as an iron(III) source. 


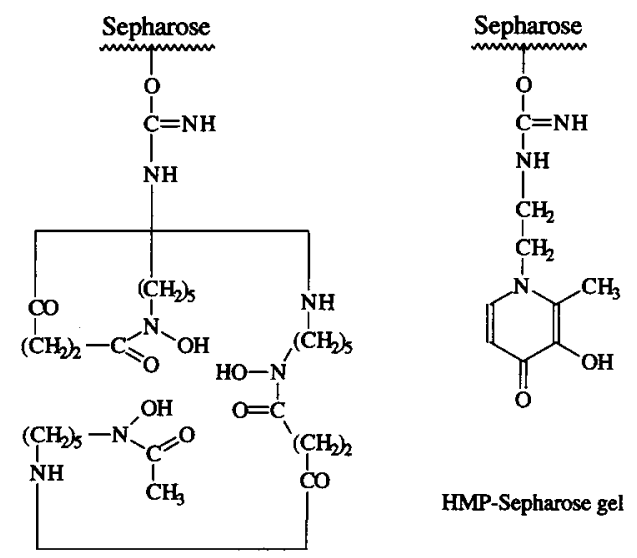

DFO-Sepharose gel
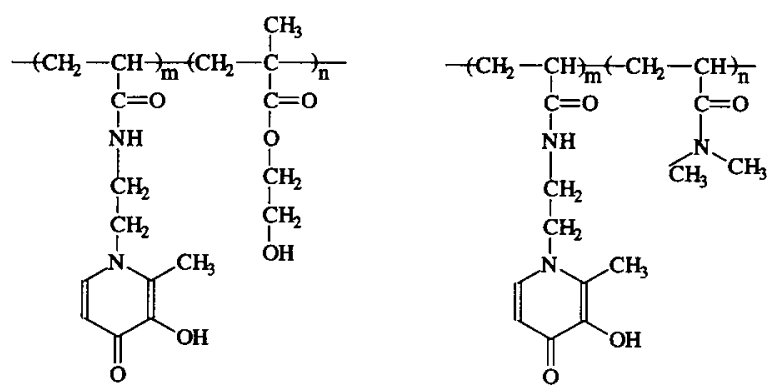

AHMP and HEMA

Crosslinked copolymers of

AHMP and DMAA

Figure 1 Structures of various iron(III) chelating resins.

The iron(III) chelated resins were prepared and analyzed as described previously. ${ }^{14}$

\section{Spectrophotometric Measurements}

UV-visible determination was carried out with a Uvikon 930 spectrophotometer. Atomic absorption spectrophotometric analysis was taken with a Perkin-Elmer Zeeman 5000 atomic absorption spectrophotometer.

\section{Stability Study of the Resins}

As an indication of the stability of the iron(III) chelating resins, the release of ligands from the resins was determined according to the procedures described previously. ${ }^{11-14}$

\section{Determination of Stability Constants}

\section{EDTA Competition Reaction}

Fresh stock solutions ( $5 \mathrm{mM}$ ) of iron(III) in water were used. EDTA solutions (10 $\mathrm{mM})$ were prepared by dissolving appropriate amounts of EDTA in phosphate buffered saline (PBS, pH 7.4), and adjusted to pH 7.1 with $1 \mathrm{M} \mathrm{NaOH}$. To a mixture of $1.5 \mathrm{ml}$ of the EDTA solution and a determined amount of the gel or resin, $2.0 \mathrm{ml}$ of the iron(III) solution and 21.5 $\mathrm{ml}$ of PBS were added. The mixture was rotated at $20^{\circ} \mathrm{C}$ for 3 days and the concentration of the soluble iron(III) complex was determined by atomic absorption spectrophotometry (AAS).

\section{EHMP Competition Reaction}

Solutions were prepared containing known amounts of iron(III) and EHMP. The experiments were performed at $20^{\circ} \mathrm{C}$ for 3 days by rotating a known amount of a chelating resin in $25 \mathrm{ml}$ of an iron(III)EHMP solution in PBS (Method A) or by rotating a known amount of an iron(III)-chelated resin with $25 \mathrm{ml}$ of EHMP solution in PBS (Method B). The concentration of the soluble complexes at equilibrium was determined by UV-visible spectrophotometry or by AAS. The equilibrium was already reached after $48 \mathrm{~h}$ because the same concentration was found after $72 \mathrm{~h}$. 
Table I Stability Constants of Iron(III)-Ligand Complexes on Various Iron(III) Chelating Resins

\begin{tabular}{|c|c|c|c|c|c|c|c|}
\hline \multirow[b]{2}{*}{ No } & \multicolumn{2}{|c|}{ Chelating Resin } & \multicolumn{2}{|c|}{ Soluble Chelator } & \multirow[b]{2}{*}{$\begin{array}{c}{[\mathrm{Fe}]_{t}} \\
(\mathrm{~m} M)\end{array}$} & \multirow{2}{*}{$\begin{array}{c}{[\mathrm{FeL}] \text { or }} \\
{\left[\mathrm{FeL}_{3}\right]} \\
(\mathrm{m} M)\end{array}$} & \multirow[b]{2}{*}{$\log K^{\prime}$} \\
\hline & Code & $\begin{array}{c}{\left[\mathrm{L}^{\prime}\right]_{t}} \\
(\mathrm{~m} M)\end{array}$ & Code & $\begin{array}{c}{[\mathrm{L}]_{t}} \\
(\mathrm{~m} M)\end{array}$ & & & \\
\hline 1 & DFO-Sepharose & 0.416 & EDTA & 0.60 & 0.40 & 0.319 & 26.6 \\
\hline 2 & HMP-Sepharose & 0.732 & EHMP & 0.80 & 0.20 & 0.062 & 37.9 \\
\hline 3 & AHMP-HEMA & 1.632 & EDTA & 0.60 & 0.40 & 0.272 & 27.2 \\
\hline 4 & AHMP-DMAA & 0.816 & EHMP & 0.80 & 0.20 & 0.0091 & 39.5 \\
\hline
\end{tabular}

\section{RESULTS AND DISCUSSION}

The stability constants for various iron(III) chelating resins are given in Table $I$. The values show that the immobilized HMP resins had a higher stability constant than the DFO-Sepharose gel, which was also reported for their free ligands. ${ }^{28}$

In order to check that an equilibrium in fact had been reached, the stability constants were determined by measurements at various competition conditions (Table II). AHMP-DMAA resin was added to a solution of a soluble iron(III)-chelator complex (Method A) or a soluble chelator was brought into contact with the iron(III) chelated resin (Method B). It was observed that the influence on the stability constant was small by changing the concentrations or by using the two methods.

The stability constant of an iron(III)-ligand complex can obviously be changed by immobilization on a polymeric matrix, which is indicated by the different stability constants of resins with the same ligand (resins No. 2, 3, and 4 in Table I). For evaluating the effect of ligand immobilization, stability constants of insoluble iron(III) complexes $\left(\log K^{\prime}\right)$ as well as those of the corresponding soluble complexes $(\log K)$ are given in Table III. From the results shown in Table III, it is evident that $\log \left(K^{\prime} / K\right)$

Table II Stability Constants of Iron(III)-Ligand Complexes on an AHMP-DMAA Resin at Various Competition Conditions

\begin{tabular}{ccccc}
\hline & $\begin{array}{c}{[\mathrm{Fe}]_{t}} \\
\text { Method }^{*}\end{array}$ & $\begin{array}{c}{[\mathrm{EHMP}]_{t}} \\
(\mathrm{~m} M)\end{array}$ & $\begin{array}{c}{\left[\mathrm{L}^{\prime}\right]_{t}} \\
(\mathrm{~m} M)\end{array}$ & $\log K^{\prime}$ \\
\hline A & 0.20 & 0.80 & 0.50 & 40.2 \\
A & 0.20 & 1.20 & 0.55 & 40.8 \\
A & 0.20 & 0.80 & 0.55 & 40.4 \\
B & 0.48 & 10.0 & 1.55 & 38.9 \\
B & 0.50 & 15.0 & 1.57 & 39.2 \\
B & 0.52 & 10.0 & 1.99 & 39.7 \\
\hline
\end{tabular}

* See Experimental. depends on the type of polymeric matrix as well as on the ligand type.

Chelating properties of a chelating resin are affected by the affinity of the ligand, steric hindrance between the ligand and the polymeric matrix, hydrophilicity, and stability of the resin..$^{13,14,29-31}$ It is quite possible that some of these factors had an influence on the stability constants of the iron(III) chelating resins. Table III shows that $\log \left(K^{\prime} / K\right)$ for the DFO-Sepharose gel was much lower than that for the HMP-Sepharose gel, whereas the same polymeric matrix was used. As indicated, a decrease in the stability constant of the iron(III)-DFO complex was observed after DFO was immobilized to the polymeric matrix. This effect is probably due to steric hindrance between the bulky DFO and the polymeric matrix, and to a decrease in mobility of the DFO molecule. On the other hand, a considerable change in the stability constant for the HMPSepharose gel was not observed, possibly because the HMP molecule is smaller, which will result in less steric hindrance between the HMP ligand and the resin.

As discussed in previous papers for the iron(III) chelating efficiencies of AHMP-HEMA and AHMP-DMAA resins, ${ }^{13,14}$ the swelling properties of the resins affected their iron(III) chelating abilities to a great extent. The difference in $\log \left(K^{\prime} / K\right)$ might reflect an effect of the hydrophilicity on the chelating affinity of the resins, and therefore the water contents of the resins are also given in Table III. The AHMP-HEMA resin had a water content of only $50 \%$; this relatively low hydrophilicity might be the reason for the decrease of the stability constant. In a similar way, the increased hydrophilicity of the AHMP-DMAA resin might be an explanation for the higher value of $K^{\prime}$.

On the other hand, although the HMP-Sepharose gel (with the same ligand as the AHMP-DMAA resin) had a higher water content $(95 \%)$, the value of $K^{\prime}$ was slightly lower than that of AHMP-DMAA. It must be noted that the stability constant may 
Table III Physiochemical Data of Various Iron(III) Chelating Resins

\begin{tabular}{lccccc}
\hline \multicolumn{1}{c}{ Resin Code } & $\log K^{\prime}$ & $\log K$ & $\log \left(K^{\prime} / K\right)$ & $\begin{array}{c}\text { Water Content } \\
(\%)^{\mathbf{a}}\end{array}$ & $\begin{array}{c}\text { Ligand Release } \\
(\%)^{\mathbf{b}}\end{array}$ \\
\hline DFO-Sepharose & 26.6 & 31 & -4.4 & 95 & 0.8 \\
HMP-Sepharose & 37.9 & 36.7 & 1.2 & 95 & 1.0 \\
AHMP-HEMA & 27.2 & 36.7 & -9.5 & 50 & 0.1 \\
AHMP-DMAA & $39.9^{\mathrm{c}}$ & 36.7 & 3.2 & 88 & 0.03 \\
\hline
\end{tabular}

Swollen at $25^{\circ} \mathrm{C}$ for $24 \mathrm{~h}$.

${ }^{b}$ Determined in water after $24 \mathrm{~h}$ at $25^{\circ} \mathrm{C}$.

' Using average value of $\log K^{\prime}$ (Table II).

also be influenced by the stability of a resin; a low stability will decrease the stability constant because some ligands release from the resin to the solution. Table III also shows the stability of the resins and it is reasonable to assume that the lower value of $K^{\prime}$ for the HMP-Sepharose gel, as compared with the AHMP-DMAA resin, probably resulted from its low stability in water. ${ }^{11,12}$

It has been reported that an increase in the stability constant of a metal-ligand complex is a general characteristic when immobilizing a ligand to a polymer. ${ }^{32}$ Results of our investigations seem to indicate that several effects are involved, which may lead to an increase or a decrease in the stability constant.

\section{CONCLUSIONS}

A method was described to determine the stability constants of iron(III)-ligand complexes on insoluble iron(III) chelating resins, i.e., DFO-Sepharose gel, HMP-Sepharose gel, AHMP-HEMA resin, and AHMP-DMAA resin.

A higher hydrophilicity and stability of a resin resulted in an increase of the stability constant, whereas steric hindrance decreased the stability constant. Stability constants of iron(III) chelating resins higher than those for the corresponding monomeric chelators were found, but in other cases immobilization gave rise to a decrease in the stability constant.

\section{REFERENCES}

1. J. R. Mahoney, Jr., P. E. Hallaway, B. E. Hedlund, and J. W. Eaton, J. Clin. Invest., 84, 1362 (1989).

2. P. E. Hallaway, J. W. Eaton, S. S. Panter, and B. E. Hedlund, Proc. Natl. Acad. Sci. USA, 86, 10108 (1989).
3. I. W. Devoe and B. E. Holbein, Eur. Pat. Appl. EP 104,346 (1984); Chem. Abstr. 1984 101, 20212 c.

4. C. M. Ambrus, S. Anthone, G. Deshpande, C. Horvath, and K. Kalghatgi, Trans. Am. Soc. Artif. Intern. Organs, 33, 749 (1987).

5. A. Winston, D. V. P. R. Varaprasad, J. J. Mettervill, and H. Rosenkrantz, J. Pharmac. Expt. Therap., 232, 644 (1985).

6. R. S. Ramirez and J. D. Andrade, J. Macromol. Sci., Chem., A10, 309 (1976).

7. D. Horowitz, S. Margel, and T. Shimoni, Biomaterials, 6, 9 (1985).

8. A. L. Crumbliss and J. M. Garrison, Inorg. Chim. Acta, 133, 281 (1987).

9. M. Kaneko and E. Tsuchida, J. Polym. Sci., Macromol. Revs., 16, 397 (1981).

10. A. E. Martell and R. J. Motekaitis, Determination and Use of Stability Constants, VCH, Inc., New York, 1988.

11. M. Feng, L. van der Does, and A. Bantjes, J. Biomater. Sci., Polym. Edn., 4, 99 (1992).

12. M. Feng, L. van der Does, and A. Bantjes, J. Biomater. Sci., Polym. Edn., 4, 145 (1992).

13. M. Feng, L. van der Does, and A. Bantjes, Eur. Polym. J., 30, 941 (1994).

14. M. Feng, L. van der Does, A. Bantjes, J. Appl. Polym. Sci., 52, 21 (1994).

15. C. Liu, H. Chang, and C. Hu, Inorg. Chim. Acta, 172, 151 (1990).

16. H. P. Gregor, L. B. Luttinger, and E. M. Loebl, $J$. Phys. Chem., 59, 34 (1955).

17. S. Ahrland, A. Dahlgren, and I. Persson, Acta Agric. Scand., 40, 101 (1990).

18. A. Winston and D. Kirchner, Macromolecules, 11, 597 (1978).

19. G. Schwarzenbach and K. Schwarzenbach, Helv. Chim. Acta, 46, 1390 (1963).

20. D. D. Perrin, Stability Constants of Metal-Ion Complexes: Part B, Organic Ligands, Pergamon Press, Oxford, 1979.

21. A. E. Martell and R. M. Smith, Critical Stability Constants, Plenum Press, New York, 1977.

22. G. J. Kontoghiorghes, L. Sheppard, and S. Chambers, Drug Res., 37, 1099 (1987).

23. M. Feng, L. van der Does, and A. Bantjes, J. Med. Chem., 36, 2822 (1993). 
24. G. J. Kontoghiorghes, Inorg. Chim. Acta, 135, 145 (1987).

25. G. J. Kontoghiorghes, L. Sheppard, and J. Barr, Inorg. Chim. Acta, 152, 195 (1988).

26. R. J. Motekaitis and A. E. Martell, Inorg. Chim. Acta, 183, 71 (1991).

27. G. J. Kontoghiorghes and L. Sheppard, Inorg. Chim. Acta, 136, L11 (1987).

28. R. C. Hider and A. D. Hall, Persp. Bioinorg. Chem., 1, 209 (1991).

29. L. R. Melby, J. Am. Chem. Soc., 74, 4044 (1975).
30. L. Janus, J. Morcellet, M. Delporte, and M. Morcellet, Eur. Polym. J., 28, 1185 (1992).

31. S. Atsushi, O. Naotake, H. Kumiko, and N. Koichi, Anal. Sci., 4, 399 (1988).

32. H. F. Mark, N. M. Bikales, C. G. Overberger, and G. Menges, Encyclopedia of Polymer Science and Engineering, Vol. 3, John Wiley \& Sons, Inc., 1985.

Received January 26, 1994

Accepted April 16, 1994 